\title{
Mix design for improved strength and freeze-thaw durability of pervious concrete fill in
} Pearl-Chain Bridges

\author{
Lund, Mia Schou Møller; Kevern, John T.; Schaefer, Vernon R.; Hansen, Kurt Kielsgaard
}

Published in:

Materials and Structures

Link to article, DOI:

10.1617/s11527-016-0907-4

Publication date:

2017

Document Version

Peer reviewed version

Link back to DTU Orbit

Citation (APA):

Lund, M. S. M., Kevern, J. T., Schaefer, V. R., \& Hansen, K. K. (2017). Mix design for improved strength and freeze-thaw durability of pervious concrete fill in Pearl-Chain Bridges. Materials and Structures, 50(42). https://doi.org/10.1617/s11527-016-0907-4

\section{General rights}

Copyright and moral rights for the publications made accessible in the public portal are retained by the authors and/or other copyright owners and it is a condition of accessing publications that users recognise and abide by the legal requirements associated with these rights.

- Users may download and print one copy of any publication from the public portal for the purpose of private study or research.

- You may not further distribute the material or use it for any profit-making activity or commercial gain

- You may freely distribute the URL identifying the publication in the public portal 


\title{
Mix design for improved strength and freeze-thaw durability of pervious concrete fill in Pearl-Chain Bridges
}

\author{
Mia S. M. Lund · John T. Kevern · Vernon R. Schaefer · Kurt K. Hansen
}

Received: date / Accepted: date

\begin{abstract}
Pearl-Chain Bridges are an innovative precast arch bridge technology which can utilize pervious concrete as fill material. The present study investigates how the mix design of the pervious concrete fill can be influenced by use of an air-entraining admixture, a high-range water reducing admixture, fibers, and by internal curing using lightweight aggregate to best possibly meet the requirements for a fill material in Pearl-Chain Bridges. The 28-day compressive strength, splitting tensile strength, shear strength, permeability, and freeze-thaw durability were determined and compared for eight different mixture proportions using two different sizes of granite coarse aggregate and at two different water-to-cement ratios. The specimens had an average void content of $24-28 \%$. Specimens containing air entraining and high-range water reducing admixtures were most workable, as determined by fresh density, and thus the easiest to place. The addition of a high-range water reducing admixture and lightweight sand (expanded shale) for internal curing improved the 28-day compressive strength and splitting tensile strength. The coarse aggregate gradation had a large influence on permeability; however, all tested permeabilities were high enough to drain the rain from a 100-year rain event in Denmark. The air entraining agent dosage used was not sufficiently high to create the necessary protective
\end{abstract}

M.S.M. Lund $\cdot$ K.K. Hansen

Technical University of Denmark, Brovej 118, DK-2800 Kgs. Lyngby, Denmark

E-mail: msml@byg.dtu.dk, kkh@byg.dtu.dk

J.T. Kevern

University of Missouri-Kansas City, 352 Flarsheim Hall, 5100 Rock-

hill Rd. Kansas City, MO 64110, USA

E-mail: kevernj@umkc.edu

V.R. Schaefer

Iowa State University, Dept. of Civil, Construction, and Environmental

Engineering, Ames, IA 50011, USA

E-mail:vern@iastate.edu air content in the cement paste, and the freeze-thaw durability of the specimens were generally poor for the utilized test procedure; however, the mix design containing lightweight sand showed improved freeze-thaw durability compared to the other mix designs.

Keywords Fill material · Freeze-thaw durability · PearlChain Bridge $\cdot$ Permeability $\cdot$ Pervious concrete $\cdot$ Strength properties

\section{Introduction}

Pearl-Chain Bridge (PCB) technology is a new prefabricated arch bridge concept developed primarily for road and railway bridges. Arches are no longer a widely utilized shape for new bridges because construction typically requires a comprehensive scaffolding that is both expensive, cumbersome, and closes down the underpassing road for weeks. PCB reintroduces the arch structure as an economic rapid bridge construction solution because the construction of the arch is moved to the roadside, by which the underpassing road only needs to close down when the arch is lifted into place by a crane and spandrel walls are installed. Placing the entire arch structure is only expected to take a night. The construction of PCB arch is fairly simply: a number of plane concrete elements with inclined end surfaces (so-called SLDecks (Hertz et al., 2014; Hertz, 2015)) is collected on a wire, like pearls on a string, and by post-tensioning the wire the arch is assembled (Halding et al., 2015). During the post-tensioning process the SL-Decks arch due to bearing on the inclined ends. The number of elements controls the span length and the width of the bridge is determined by the number of Pearl-Chain arches placed next to each other. In 2015, the first PCB was constructed in Denmark. The bridge consisted of a main arch with a span length of $13 \mathrm{~m}$ and two adjacent half-arches with a span length of $6.5 \mathrm{~m}$ each. The 
pile height was $0.9 \mathrm{~m}$ and the total width was $6.1 \mathrm{~m}$. The bridge was filled with Portland Cement Pervious Concrete (PCPC) as seen in Fig. 1 and described in Lund et al. (2016).
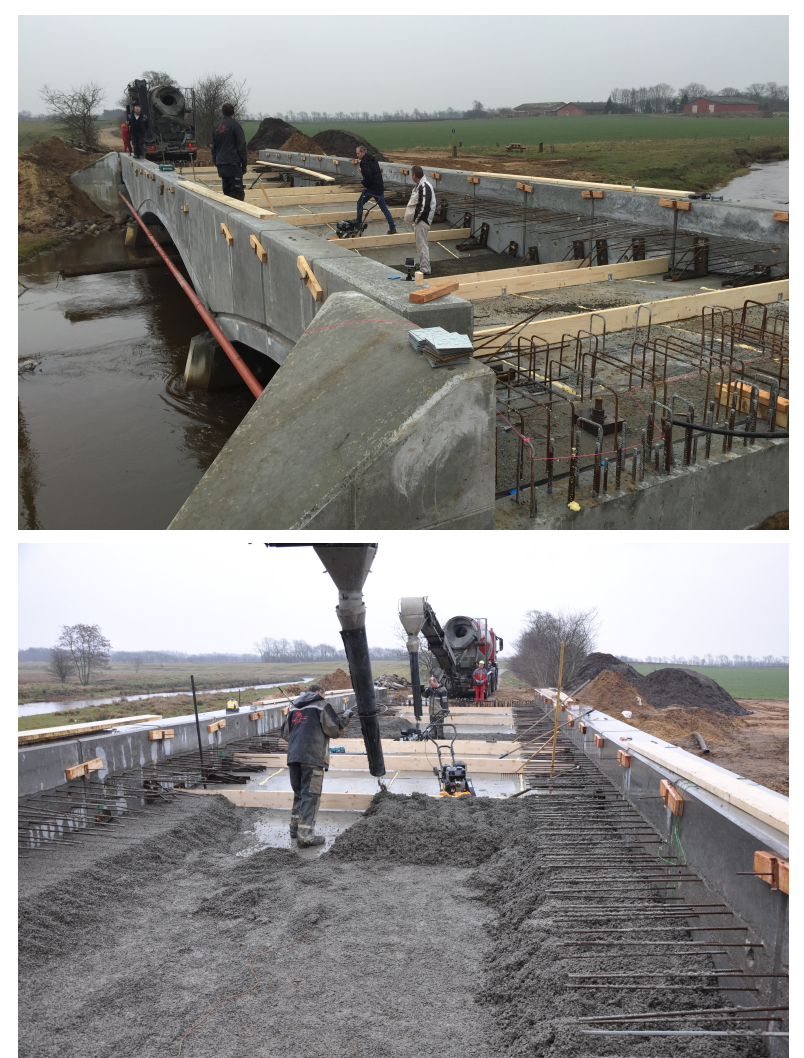

Fig. 1 PCPC cast as fill material in the very first Pearl-Chain Bridge constructed in Denmark in 2015. Upper: The longitudinal bridge section shows that the bridge consisted of a main arch between two adjacent half arches. Lower: Placement of PCPC fill. The formwork wood beams were removed as the different layers were cast.

The decision to use PCPC as the fill material rather than a more commonly used material, such as coarse aggregate, was based on several considerations taking both the strength and durability properties of the fill material and the entire PCB into account. From a durability perspective, a bridge is a sensitive point in a road construction because it is more vulnerable to the environment than the rest of the road construction. A bridge is, for example, cooled from the underside as well as from the topside during winter months which makes it more exposed to frost damages. Water is unwanted in any bridge superstructure because it is involved in most deterioration mechanisms of concrete such as freeze-thaw. PCPC fill has excellent drainage properties that prevent water accumulation in the fill, thus minimizing the risk of frost damage of the fill material itself. Moreover, water that penetrates the fill material and reaches the upper surface of the arch structure drains naturally toward the bridge ends because of the arch curvature, which minimizes the moisture exposure of the PCB arch. With a permeability of at least $4 \times 10^{-3} \mathrm{~cm} / \mathrm{s}$, the PCPC fill can drain the rain from a 10 year rain event in Denmark (IDA Wastewater Commission, 2006). Another advantage of implementing PCPC fill in PCB is that it can be incorporated as a structural part and contribute to the load-carrying capacity of the superstructure. Hence, the implementation of PCPC as fill in PCB is expected to improve the longevity and strength of the bridges. For most applications, the requirements of the strength properties of a PCPC fill are a 28-day compressive strength and 28-day splitting tensile strength of a minimum of $10 \mathrm{MPa}$ and $1 \mathrm{MPa}$, respectively. However, for certain applications, these requirements are raised, and the potential range of PCPC strength properties should therefore be known. The PCPC shear strength is not a parameter that is typically reported in the literature because PCPC is seldom applied in constructions in which its shear capacity is critical. However, in PCB the PCPC fill material can be designed to transfer shear stresses between the road surface and the PCB arch if the shear capacity of the PCPC fill is known and sufficient, and therefore it is very relevant for the application of PCPC fill in PCB to measure shear strength.

The present study investigates how the mixture proportions of PCPC can be improved to provide the most suitable fill for PCB; however, the findings also apply to other PCPC applications. This was investigated by considering the influence of air entraining admixture (AEA), high-range water reducing admixture (HRWR), polypropylene fibers, and internal curing using expanded shale lightweight aggregate on strength (compressive strength, splitting tensile strength and shear strength), permeability, and freeze-thaw durability of the same PCPC mix design as was used for the fill in the very first Pearl-Chain Bridge.

\section{Background}

PCPC is a highly permeable concrete that is typically used for permeable pavements to rapidly drain and remove rainwater from the pavement surface. Common uses include lowdensity roads and parking areas (Tennis et al., 2004). Permeability typically ranges from $0.20-0.54 \mathrm{~cm} / \mathrm{s}$ and is achieved through a large interconnected void structure with a significant void content of typically 11-35\% (Schaefer et al., 2006). PCPC consists of cement, water, and a single-sized coarse aggregate that is used to maximize the void content. However, often a small portion of the coarse aggregate volume is replaced by fine aggregate (sand) because it improves the strength and durability significantly (Kevern et al., 2008). The maximum void content is achieved by designing PCPC to have just enough cement paste to coat the aggregates and bind them together in the contact points between the aggregates. Hence, PCPC may have less cement paste than conventional Portland cement concrete. The water-to-cement ra- 
tio (w/c-ratio) of PCPC is typically $0.27-0.34$, which produces a stiff material and in many cases makes the slump test ill-suited for PCPC workability measurements (Tennis et al., 2004).

The void content of PCPC is a function of the compaction energy, aggregate gradation, and cementitious paste content. Because of the high amount of voids, the strength of PCPC is usually lower than that of conventional Portland cement concrete. Strength and unit weight decrease linearly with increasing void content (Lund et al., 2016; Schaefer et al., 2006). However, addition of chemical admixtures such as AEA, HRWR, and hydration stabilizers (HS) affect the strength properties positively, and 28-day compressive strengths of up to $28 \mathrm{MPa}$ can be achieved (Tennis et al., 2004; Kevern et al., 2008). Moreover, it has previously been found that by replacing the small portion of conventional concrete sand with pre-wetted lightweight sand for internal curing, both the the compressive strength and the splitting tensile strength increase (Kevern, 2013).

The void structure of PCPC is more complex than that of conventional Portland cement concrete because it is combined by larger water carrying voids and smaller natural and entrained air bubbles in the cement paste. The freezethaw durability of PCPC is often a major durability concern because of the larger voids; however, the open void structure is only critical if the voids become water saturated and freeze. The freeze-that durability of PCPC is improved by creating a sufficiently fine entrained air system in the cement paste. Addition of first of all AEA but also fibers and lightweight sand have been found to improve the freeze-thaw durability (Kevern, 2013; Kevern et al., 2015; NRMCA, 2004). American Society for Testing and Materials (ASTM) C666 (ASTM C666, 2008) is typically used to test and determine the freeze-thaw durability of PCPC; however, many examples show that air-entrained PCPC performs much better in the field than in the laboratory. According to ASTM C666 (ASTM C666, 2008), the PCPC specimens are fully submerged in water during laboratory testing which can be considered a worst-case scenario that is not representative of field conditions where the PCPC drainage effect naturally occurs (Henderson and Tighe, 2012). In the field, PCPC pavements perform well over several years in areas that undergo a large number of annual freeze-thaw cycles, provided it remains unsaturated (NRMCA, 2004). Even though a more realistic frost test method is needed for PCPC, ASTM C666 (ASTM C666, 2008) provides a consistent test method to compare different PCPC mix designs.

\section{Methods}

\subsection{Material properties}

All mixes were prepared with ASTM C150 cement meeting both Type I and Type II classification and ASTM C618 Class F fly ash with a specific gravity of 3.15 and 2.28 , respectively (ASTM C150, 2012; ASTM C618, 2012). The fly ash had $0.1 \%$ carbon content measured using the Eltra carbon analyzer and $0.0 \%$ loss on ignition as determined in accordance with ASTM C311 (ASTM C311, 2013). Two different types of coarse aggregate were used: granite $\mathrm{A}$ and $B$ with a maximum aggregate size of $12.7 \mathrm{~mm}$ (1/2 in.) and $9.5 \mathrm{~mm}$ (3/8 in.), respectively, both from Minnesota, USA. The specific gravity and absorption were 2.70 and $0.6 \%$ for granite $\mathrm{A}$, and 2.70 and $0.7 \%$ for granite $\mathrm{B}$, respectively. A sieving analysis was performed in accordance with ASTM C136 (ASTM C136, 2006), and Fig. 2 shows the gradation curves.

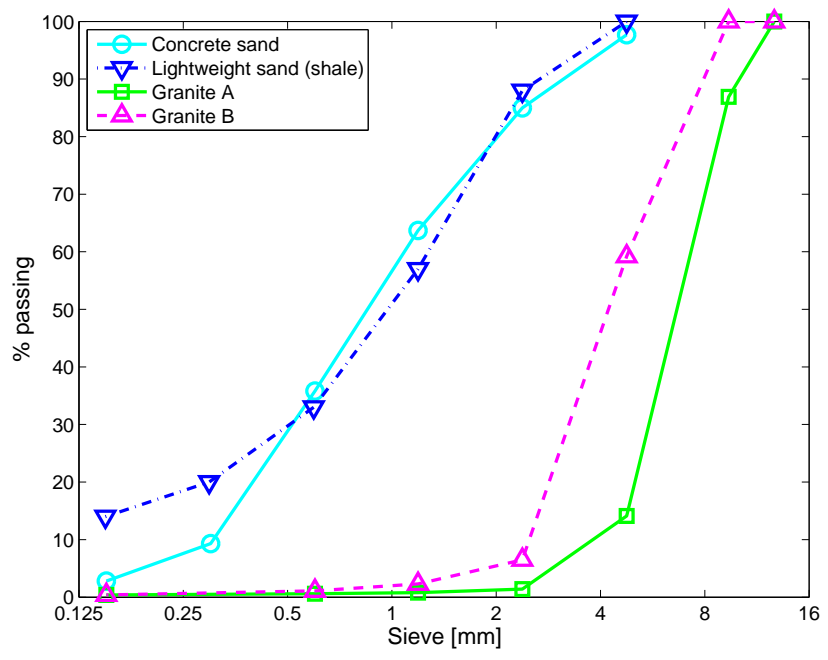

Fig. 2 Gradation curves for concrete sand, lightweight sand (expanded shale) and granite A and granite $\mathrm{B}$.

The dry rodded unit weight (DRUW) and the void ratio were measured in accordance with ASTM C29 (ASTM C29, 2009), and the results are summarized in Table 1. The gradation of granite $\mathrm{B}$ was finer than that of granite $\mathrm{A}$ and had a larger void ratio.

Table 1 Dry rodded unit weight (DRUW) and specific gravity of coarse aggregates.

\begin{tabular}{c|cccc}
\hline & $\begin{array}{c}\text { DRUW } \\
{\left[\mathrm{kg} / \mathrm{m}^{3}\right]}\end{array}$ & $\begin{array}{c}\text { Void ratio } \\
{[\%]}\end{array}$ & $\begin{array}{c}\text { Spec. gravity } \\
{[-]}\end{array}$ & $\begin{array}{c}\text { Absorption } \\
{[\%]}\end{array}$ \\
\hline Granite A & 1524 & 43 & 2.70 & 0.6 \\
Granite B & 1405 & 48 & 2.70 & 0.7 \\
\hline
\end{tabular}


As fine aggregate, concrete sand with a fineness modulus of 3.1, a specific gravity of 2.64 and $1.8 \%$ absorption was used. Moreover, expanded shale with a dry bulk specific gravity of 1.75 and a 72 hour absorption of $16 \%$ was used. Fig. 2 shows the gradation of the concrete sand and of the lightweight sand. Finally, vinsol resin-based air entraining agent and polycarboxylate based high-range water reducer with specific gravities of 1.02 and 1.10, respectively, and polypropylene fibrillated fibers with a specific gravity of 0.91 , a graded length between $12.7 \mathrm{~mm}$ and $19.1 \mathrm{~mm}$ and a specific surface area of $20.65 \mathrm{~cm}^{2} / \mathrm{g}$ were used.

\subsection{Mixture proportions}

A total of eight mixes were placed for this study. Three used granite A (Mix A) and five used granite B (Mix B). A baseline mixture consisting of cement, fly ash, water, AEA, granite and concrete sand was prepared with both granites. Different variations of the baseline mix were investigated to improve the strength and freeze-thaw durability. A mix without AEA was also prepared to consider the influence of AEA. The key for the different mix designs was as follows:

- Mix 1: No admixtures

- Mix 2: Baseline mixture with air entrainment

- Mix 3: Air entrainment and high-range water reducer

- Mix 4: Air entrainment and fibers

- Mix 5: Air entrainment and lightweight sand (expanded shale)

Mixtures 1-3 were prepared with both granite A and granite B, whereas mixtures 4-5 were only prepared with granite $\mathrm{B}$.

All mixtures were prepared with a constant amount of cement paste, and $20 \%$ cement replaced with fly ash, by weight, to improve workability, later age strength and sustainability. Mix A and B had a w/c-ratio of 0.29 and 0.31 , respectively. The fine aggregate to coarse aggregate ratio was 0.09 , also by weight. Furthermore, all mixes were designed to have a void content of $18 \%$ in addition to $3 \%$ entrained air (21\% total air), except from Mix 1-A and Mix 1-B that did not include AEA. The AEA dosage was slightly higher than the standard dosage used for conventional concrete, that is, $0.125 \%$ of the cementitious material mass. The HRWR dosage was $0.375 \%$. The amount of fibers corresponded to $0.9 \mathrm{~kg} / \mathrm{m}^{3}$. In mixes where concrete sand was replaced by lightweight sand, the mass of lightweight sand was based on a volume consideration to keep the volume of fine aggregate constant. Table 2 shows the mixture proportions for Mix A and Mix B.

\subsection{Mixing and sample preparation}

Mixtures were prepared by first mixing the aggregates and $5 \%$ of the cement in a $0.04 \mathrm{~m}^{3}$ rotating-drum mixer for one minute in order to coat all aggregates with cement to improve the PCPC strength (Schaefer et al., 2006). The AEA was diluted in the water and added to the mix. When foam was observed, fly ash and the rest of the cement was added and mixed for three minutes. The mixture was allowed to rest for three minutes and mixed for additionally two minutes before preparing the samples. In mixes with HRWR, one third of the water was held back, mixed with HRWR and added when the mix appeared uniform after addition of cement and fly ash. In mixtures containing fibers, the fibers were added together with the aggregates and 5\% of the cement in the very beginning, and mixed until the fibers were visually uniformly dispersed. In the mixture containing lightweight sand, the lightweight sand was pre-wetted for 72 hours before use (ASTM C1761, 2013). The lightweight sand was allowed to drain for 60 minutes before mixing, and the mix design was adjusted according to the moisture content of the lightweight sand measured immediately prior mixing.

Cylinder samples were prepared in d100/h200 mm (4 in $\times 8$ in.) cylinder molds for strength and permeability tests and in $75 \times 100 \times 400 \mathrm{~mm}(3 \times 4 \times 16$ in. $)$ beam molds for freeze-thaw tests. The mass of PCPC corresponding to the volume of the mold was determined from the mix design density and placed in the mold in three equal lifts. For the cylinder specimens, each layer was rodded a maximum of 25 times, depending on the particular mix design. The more workable the mixture was, the fewer times was each layer rodded. For the beams, each layer was rodded a maximum of 75 times. The layers were meshed together by vibrating each new layer for three seconds. For some of the specimens, extra mass had to be added because they compacted better than expected from the mix design; however, for other specimens it was not possible to fill all mass into the mold. The samples were demolded after 24 hours and cured in a fog room with a relative humidity $>98 \%$ until 28 days in accordance with ASTM C192 (ASTM C192, 2014).

\subsection{Testing procedures}

\subsubsection{Fresh unit weight}

Because of the stiff consistency it was not possible to assess the workability of PCPC from a standard slump cone test. Instead, the workability of fresh PCPC mixtures was determined by assessing the fresh unit weight (UW) immediately after mixing in accordance with ASTM C1688 (ASTM C1688, 2013). The method prescribes that a defined compaction energy is applied to a specified PCPC volume, 
Table 2 Mixture proportions for Mix A and Mix B with w/c $=0.29$ and w/c $=0.31$, respectively.

\begin{tabular}{l|ccc|ccccc}
\hline Mix & $1-A$ & $2-A$ & $3-A$ & $1-B$ & $2-B$ & $3-B$ & $4-B$ & $5-B$ \\
\hline Cement $\left[\mathrm{kg} / \mathrm{m}^{3}\right]$ & 315 & 315 & 315 & 315 & 315 & 315 & 315 & 315 \\
Fly ash $\left[\mathrm{kg} / \mathrm{m}^{3}\right]$ & 64 & 64 & 64 & 64 & 64 & 64 & 64 & 64 \\
Water $\left[\mathrm{kg} / \mathrm{m}^{3}\right]$ & 100 & 100 & 100 & 114 & 114 & 114 & 114 & 114 \\
Granite $\left[\mathrm{kg} / \mathrm{m}^{3}\right]$ & 1435 & 1385 & 1382 & 1401 & 1350 & 1347 & 1350 & 1350 \\
Concrete sand $\left[\mathrm{kg} / \mathrm{m}^{3}\right]$ & 133 & 128 & 128 & 130 & 125 & 125 & 125 & - \\
LW sand $\left.(\mathrm{ssd})^{*}\right)\left[\mathrm{kg} / \mathrm{m}^{3}\right]$ & - & - & - & - & - & - & - & 96.2 \\
AEA $\left[\mathrm{kg} / \mathrm{m}^{3}\right]$ & - & 0.47 & 0.47 & - & 0.47 & 0.47 & 0.47 & 0.47 \\
HWRW $\left[\mathrm{kg} / \mathrm{m}^{3}\right]$ & - & - & 1.42 & - & - & 1.42 & - & - \\
Fibers $\left[\mathrm{kg} / \mathrm{m}^{3}\right]$ & - & - & - & - & - & - & 0.89 & - \\
\hline
\end{tabular}

* The 'saturated surface dry' (ssd) state is defined as the state at which the lightweight sand is water saturated to its 72 hour absorption value.

and by weighing this compacted volume of PCPC, the fresh UW is obtained. The fresh UW was measured immediately after mixing ( 5 minutes after water addition), and again 2 hours after water addition to consider the stiffening with time. During the time between water addition and the second fresh UW measurement the PCPC mixture was left in the mixer and rotated every 15 minutes.

\subsubsection{Hardened unit weight and void content}

The hardened UW and the void content of the specimens were determined in accordance with ASTM C1754 (ASTM C1754, 2012). Three cylinder specimens of all mixes were oven dried at $38^{\circ} \mathrm{C}$ and weighed every 24 hours until the difference between any two subsequent mass determinations was less than $0.5 \%$. Subsequently, the specimens were submerged in water for 30 minutes and trapped air was released by tapping the sides of the specimens 10 times with a rubber mallet. Based on the weight of the specimen under water, the void content, $P[\%]$, of the specimen was determined from Archimedes' principle using the formula:

$P=\left(1-\frac{m_{38^{\circ} \mathrm{C}}-m_{s w}}{\rho_{w} V_{t o t}}\right) \times 100 \%$

Where: $m_{38}{ }^{\circ} \mathrm{C}[\mathrm{kg}]$ is the constant mass of the oven-dried specimen, $m_{s w}[\mathrm{~kg}]$ is the mass of the specimen submerged in water, $\rho_{w}\left[\mathrm{~kg} / \mathrm{m}^{3}\right]$ is the water density, and $V_{t o t}\left[\mathrm{~m}^{3}\right]$ is the total volume of the specimen.

The hardened UW of the same specimens as used for the void content determination was found as the ratio between $m_{38^{\circ} \mathrm{C}}$ and $V_{t o t}$. Afterwards, a linear relationship between the hardened UW and the void content was obtained. Before oven drying, the specimens were placed on a wrung towel and allowed to drain for 30 minutes before weighing. Hence, another UW relating to this moisture content was obtained and also correlated to the void content of the specimens.

\subsubsection{Strength test setups}

When removed from the fog room at 28 days, the specimens were allowed to drain on a wrung towel for 30 minutes. Subsequently, they were weighed by which their UW was determined, and the linear relationship between the hardened UW and the void content could be used to determine the void content of the specimens.

The compressive strength was determined in accordance with ASTM C39 (ASTM C39, 2014) using sulfur capping. In addition to sulfur capping, the compressive strength was also performed with $4.7 \mathrm{~mm}$ (3/16 in.) thick plywood placed between the testing machine and the specimen ends. Three specimens were tested for each type of compressive strength test and for each mix design. The splitting tensile strength was determined in accordance with ASTM C496 (ASTM C496, 2011) and six specimens were tested for each mix design. The shear strength was tested according to Iowa DOT test method 406-C (Test Method No. Iowa 406-C, 2000) by placing the cylinder horizontally in the space between the two circular halves of the testing jig, see Fig. 3(left). A constant load at a rate of $2.8-3.4 \mathrm{MPa} / \mathrm{min}$. was subsequently applied over the cross section of the specimen at the specimen mid-height until the specimen failed. Three specimens were tested for each mix design.

\subsubsection{Permeability test setup}

Permeability was determined using a falling head test setup. The cylinder end surfaces were cut off to obtain a uniform sample with a length of $15 \mathrm{~cm}$. The cylinders were sealed in PVC shrink wrap, and rubber sleeves were tightened around the cylinder top and bottom with hose clamps, see Fig. 3(right). The initial water head was approximately $22.9 \mathrm{~cm}$ (9 in.) and the final water head was approximately $2.5 \mathrm{~cm}$ (1 in.). The permeability coefficient, $k[\mathrm{~cm} / \mathrm{s}]$, was determined using the formula:

$k=\frac{a L}{A t} \ln \left(\frac{h_{1}}{h_{2}}\right)$ 


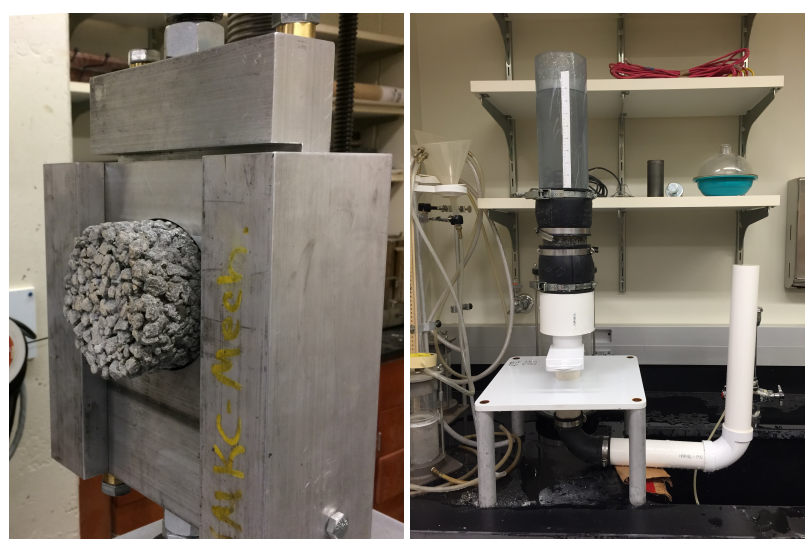

Fig. 3 Left: Shear test setup according to Iowa DOT test method 406C. Right: Falling head permeability test setup.

Where: $a\left[\mathrm{~cm}^{2}\right]$ is the cross-sectional area of the standpipe, $L[\mathrm{~cm}]$ is the height of the specimen, $A\left[\mathrm{~cm}^{2}\right]$ is the crosssectional area of the specimen, and $t[\mathrm{~s}]$ is the time between the initial head $h_{1}[\mathrm{~cm}]$ and the final head $h_{2}[\mathrm{~cm}]$.

\subsubsection{Freeze-thaw test setup}

The freeze thaw durability was evaluated from ASTM C666 Procedure A (ASTM C666, 2008), where beam specimens are frozen and thawed in water and the core temperature varies between $-18 \pm 2^{\circ} \mathrm{C}$ and $4 \pm 2^{\circ} \mathrm{C}$ during a freeze-thaw cycle. Prior to the beginning of the freeze-thaw exposure, the specimens were water saturated for 24 hours at $4^{\circ} \mathrm{C}$. The mass loss and the durability factor $(D F)$ calculated from relative dynamic modulus were used to evaluate the freezethaw durability of the specimens, and the tests were terminated when the specimens reached $15 \%$ mass loss, 300 frost cycles, or a reduction in the relative dynamic modulus to $60 \%$. The mass loss and the transverse frequency were measured every 30 cycles. $D F[\%]$ was calculated using the formula:

$D F=\frac{P N}{M}$

Where: $P[\%]$ is the relative dynamic modulus at $N$ cycles, $N$ is the number of cycles at which $P$ reaches the specified minimum value for discontinuing the test-chosen as $60 \%$ of the relative dynamic modulus - or the specified number of cycles at which the exposure is to be terminated, whichever is less, and $M=300$ cycles is the number of cycles at which the exposure is to be terminated. The relative dynamic modulus at $c$ cycles, $R D M_{c}[\%]$, was calculated using the formula:

$R D M_{c}=\frac{n_{c}^{2}}{n^{2}} \times 100 \%$

Where: $n_{c}$ is the fundamental transverse frequency after $c$ frost cycles and $n$ is the fundamental transverse frequency after 0 frost cycles.
In total, three beam specimens were tested for each of the mix designs except from Mix 1-A that was not tested.

\section{Results and discussion}

\subsection{Fresh and hardened unit weight and void content}

Results for workability, hardened unit weight, and void content are shown in Table 3. The void content also includes entrained air voids that became water filled during the testing procedure. Void content was measured individually for both cylinder specimens used for strength and permeability tests and for beam specimens used for freeze-thaw tests.

The fresh UW in Table 3 relates to the values measured immediately after mixing (5 minutes after water addition) and 2 hours after water addition (Section 3.4.1). Typically, concrete is not constantly mixed for a long period in the lab. However, the high degree of friction, exposed surface area, and low w/c-ratio of PCPC results in rapid stiffening of the material during transport. Since the strength is linearly related to unit weight, any increases in void content due to stiffening directly result in lower strength. Ideally recommended PCPC mixtures should have consistent unit weight values between the initial test and the later test. The difference between these unit weights is considered the stiffening with time. Mix 3-B containing HRWR had the highest fresh UW which indicates that this mix had the best initial workability. On the other hand, Mix 1-B that did not contain AEA had the lowest fresh UW which indicates that this mix was the stiffest mix with the poorest workability. Thus, AEA and HRWR positively effect the workability of PCPC. There was not observed any influence from fibers or lightweight sand on the fresh UW. Considering the stiffening with time, Mix 2-B experienced a larger difference in fresh UW than any of the other mixes. This means that the workability of Mix 2-B became stiffer compared to the other mixes and therefore was harder to place. Mix 5-B contained the expanded shale lightweight aggregate for internal curing and experienced much less stiffening over the mixing period than the other mixtures containing AEA.

The variability on the hardened UW and the void content was low and within reported variability of the test method in ASTM C1754 (ASTM C1754, 2012) for all mixes except from Mix 2-B that exceeded reported single-operator $\mathrm{COV}$ of 5.82\%. This might be related to Mix 2-B stiffening with time by which a larger variation in the void content is expected, as considered above. The void content of all mixes was higher than the void content estimated in the mix design because some water that was not bound by cement and fly ash evaporated during the oven drying along with the extra water added to satisfy aggregate absorption. Moreover, the void content of mixes with granite B was slightly lower than 
Table 3 Fresh unit weight (UW) measured 5 minutes and 2 hours after water addition, hardened UW, and void content of all mixes for both cylinder and beam specimens. Average (avg.) values as well as coefficients of variation (COV) are shown.

\begin{tabular}{|c|c|c|c|c|c|c|c|c|c|}
\hline \multirow[b]{2}{*}{ Mix } & \multicolumn{3}{|c|}{ Fresh UW $\left[\mathrm{kg} / \mathrm{m}^{3}\right]$} & \multicolumn{2}{|c|}{ Hardened UW } & \multicolumn{2}{|c|}{ Voids, cyl. } & \multicolumn{2}{|c|}{ Voids, beam } \\
\hline & $\begin{array}{c}\text { (A) } \\
5 \mathrm{~min} .\end{array}$ & $\begin{array}{l}\text { (B) } \\
2 \mathrm{~h}\end{array}$ & (A)-(B) & $\begin{array}{l}\text { Avg. } \\
{\left[\mathrm{kg} / \mathrm{m}^{3}\right]}\end{array}$ & $\begin{array}{c}\mathrm{COV} \\
{[\%]}\end{array}$ & $\begin{array}{l}\text { Avg. } \\
{[\%]}\end{array}$ & $\begin{array}{l}\mathrm{COV} \\
{[\%]}\end{array}$ & $\begin{array}{l}\text { Avg. } \\
{[\%]}\end{array}$ & $\begin{array}{c}\mathrm{COV} \\
{[\%]}\end{array}$ \\
\hline $1-A^{*}$ & - & - & - & 1840 & 1.8 & 28.0 & 5.5 & - & - \\
\hline $2-A^{*}$ & - & - & - & 1865 & 1.0 & 27.4 & 2.9 & 19.4 & 0.6 \\
\hline $3-\mathrm{A}^{*}$ & - & - & - & 1847 & 0.6 & 27.7 & 2.7 & 18.5 & 1.0 \\
\hline 1-B & 1840 & 1794 & 46 & 1858 & 0.6 & 25.0 & 2.5 & 18.8 & 2.5 \\
\hline $2-B$ & 1903 & 1806 & 97 & 1832 & 1.6 & 25.8 & 5.9 & 19.0 & 1.3 \\
\hline $3-B$ & 1914 & 1840 & 74 & 1827 & 1.0 & 25.8 & 5.7 & 13.8 & 5.0 \\
\hline 4-B & 1874 & 1803 & 71 & 1811 & 0.6 & 26.6 & 3.2 & 19.4 & 3.1 \\
\hline $5-B$ & 1857 & 1806 & 51 & 1805 & 0.6 & 24.4 & 3.6 & 13.3 & 3.8 \\
\hline
\end{tabular}

* The fresh UW was not measured for Mix A, and no beam specimens were cast with Mix $1-\mathrm{A}$.

that of mixes with granite A because of the difference in gradation and w/c-ratio making it easier to compact specimens with granite $\mathrm{B}$.

No particular differences in hardened UW or void content were observed within the different variants of Mix A and Mix B.

\subsection{8-day compressive strength}

The 28-day compressive strength test results are shown in Fig. 4. As mentioned, the compressive strength was determined from tests where either sulfur capping or wood end plates were used to distribute the compression force over the entire specimen cross section. There were no statistically significant differences between the average values of these two groups for any of the mix designs as determined by one-way ANOVA; hence, the results in Fig. 4 include the results from both methods. Also shown are the average void contents of the specimens tested for the particular mix designs. Fig. 4 depicts the results in a box plot where the data is shown through their quartiles. The top and bottom of each box are the first and third quartile, and the middle line is the median. The whiskers indicate the furthest data points outside the quartiles, and outliers are plotted as individual points.

The average compressive strengths are summarized in Table 4, neglecting the outliers indicated in the box plot in Fig. 4; however, it should be noted that all of the outliers had much greater strength than the corresponding samples. The variability of Mix 2-B is larger than the variability of the remaining mix designs which is believed to be connected with the correspondingly larger variability of the void content of Mix 2-B.

Fig. 4 shows that, in general, the 28-day compressive strengths of Mix B were higher than those of Mix A. As determined by one-way ANOVA there were statistically signif-

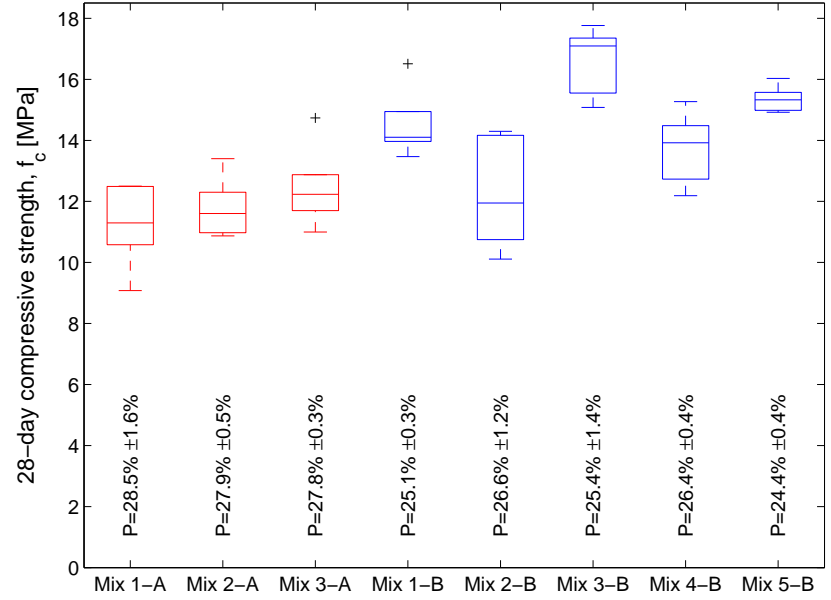

Fig. 4 Box plot of 28-day compressive strength, $\mathrm{f}_{c}$, for all mixes. The average void content for the specimens tested is also shown. Six specimens were tested for each mix design.

Table 4 28-day compressive strength $\mathrm{f}_{c}$, splitting tensile strength $\mathrm{f}_{s}$, and shear strength $\mathrm{f}_{v}$, for all mixes. Average (avg.) values as well as coefficients of variation (COV) are shown.

\begin{tabular}{c|cc|cc|cc}
\hline \multirow{2}{*}{ Mix } & \multicolumn{2}{|c|}{$\mathrm{f}_{c}$} & \multicolumn{2}{|c|}{$\mathrm{f}_{s}$} & \multicolumn{2}{c}{$\mathrm{f}_{v}$} \\
& $\begin{array}{c}\text { Avg. } \\
{[\mathrm{MPa}]}\end{array}$ & $\begin{array}{c}\mathrm{COV} \\
{[\%]}\end{array}$ & $\begin{array}{c}\text { Avg. } \\
{[\mathrm{MPa}]}\end{array}$ & $\begin{array}{c}\text { COV } \\
{[\%]}\end{array}$ & $\begin{array}{c}\text { Avg. } \\
{[\mathrm{MPa}]}\end{array}$ & $\begin{array}{c}\mathrm{COV} \\
{[\%]}\end{array}$ \\
\hline 1-A & 11.6 & 7.0 & 1.7 & 1.3 & 4.5 & 41 \\
2-A & 11.8 & 8.0 & 1.5 & 9.7 & 2.1 & 36 \\
3-A & 12.0 & 6.0 & 1.9 & 4.9 & 3.8 & 34 \\
\hline 1-B & 14.1 & 3.8 & 1.8 & 11.8 & 3.0 & 10 \\
2-B & 12.3 & 15.2 & 1.7 & 13.8 & 4.8 & 25 \\
3-B & 16.7 & 6.5 & 1.9 & 11.5 & 3.9 & 29 \\
4-B & 13.8 & 8.3 & 1.6 & 2.2 & 4.3 & 38 \\
5-B & 15.4 & 2.8 & 2.0 & 6.2 & 4.1 & 17 \\
\hline
\end{tabular}


icant differences between the average compressive strength of Mix 1-A and 1-B $\left(p=2.6 \times 10^{-5}\right)$, and Mix 3-A and 3-B $\left(p=3.8 \times 10^{-7}\right)$ with the $\mathrm{B}$ mixes having the greatest compressive strength; however, there were no statistically significant differences between the average compressive strength of Mix 2-A and 2-B ( $p=0.89$ ). The void content of Mix A specimens was slightly higher than that of Mix B specimens, because Mix B compacted better than Mix A, and therefore the compressive strengths of the Mix A specimens were also expected to be lower than those of Mix B. Mix $\mathrm{B}$ had a higher w/c-ratio than Mix A which would typically decrease the compressive strength; however, because granite B contained smaller aggregates than granite A (Fig. 2), the number of contact points between the aggregates were increased which influenced the compressive strength positively.

As determined by one-way ANOVA there were no statistically significant differences between the average compressive strength of Mix 1-A, 2-A and 3-A ( $p=0.21)$; however, for Mix B there were statistically significant differences between the average compressive strengths of Mix 1-B, 2-B, 3-B, 4-B and 5-B $\left(p=8.2 \times 10^{-6}\right)$. A paired-samples t-test showed that the average compressive strengths of Mix 1B, 3-B, 4-B and 5-B were all statistically significant different than that of Mix 2-B (the baseline mix). Table 4 shows that the greatest increase in the average 28-day compressive strength was obtained by addition of HRWR (Mix 3B) by which the strength increased $35.5 \%$ compared to the baseline mix (Mix 2-B). Also fibers and lightweight sand influenced the compressive strength positively. By adding 0.9 $\mathrm{kg} / \mathrm{m}^{3}$ fibers (Mix 4-B) and by replacing concrete sand with lightweight sand (Mix 5-B), the average 28-day compressive strength was increased by $11.9 \%$ and $25.0 \%$, respectively.

\subsection{8-day splitting tensile strength}

Fig. 5 shows the results from the 28-day splitting tensile strength tests and the average void contents of the specimens tested for the particular mix designs. The average splitting tensile strengths are summarized in Table 4, neglecting the outlier indicated in the box plot in Fig. 5. The variability on the splitting tensile strengths was all within the limits for d100/h200mm cylinders in ASTM C496 (ASTM C496, 2011).

When comparing the 28-day splitting tensile strength of Mix 1-A with Mix 1-B, Mix 2-A with Mix 2-B, and Mix 3A with Mix 3-B, one-way ANOVA showed that there were no statistically significant differences between the average splitting tensile strengths when using granite B rather than granite A while increasing the w/c-ratio from 0.29 to 0.31 . The increased number of contact points due to the reduction in coarse aggregate gradation did therefore not have the same positive influence on the splitting tensile strength as on

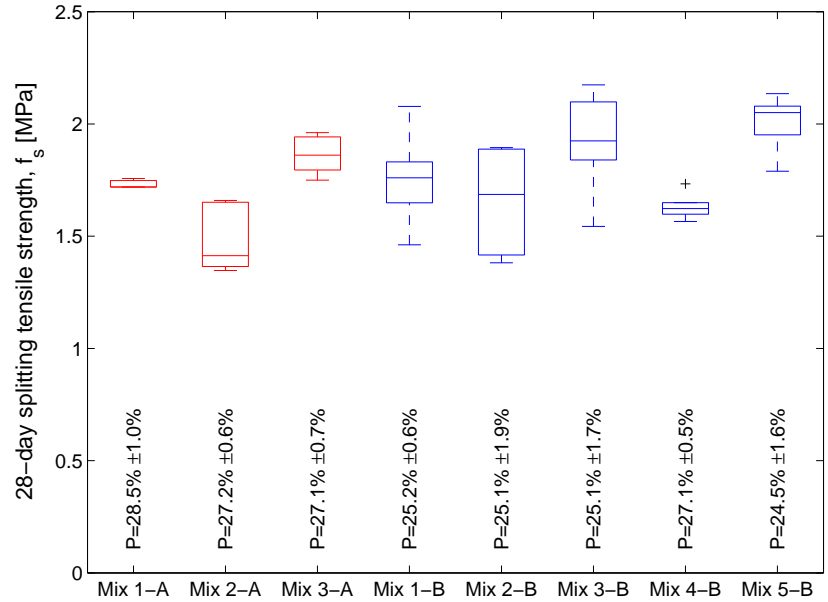

Fig. 5 Box plot of 28-day splitting tensile strength, $\mathrm{f}_{s}$, for all mixes. The average void content for the specimens tested is also shown. Six specimens were tested for each mix design.

the compressive strength. As with the specimens tested for compressive strength, the void content of specimens of Mix A was higher than that of specimens of Mix B, because Mix B compacted better than Mix A.

As determined by one-way ANOVA and paired-samples t-test there were statistically significant differences between the average splitting tensile strength of Mix 1-A and 2-A $\left(p=5.8 \times 10^{-3}\right)$, and Mix 2-A and 3-A $\left(p=5.3 \times 10^{-5}\right)$. The 28-day splitting tensile strength increased $26.5 \%$ when adding HRWR (Mix 3-A) to the baseline mix (Mix 2-A).

For Mix B, one-way ANOVA and paired-samples t-test showed that the average splitting tensile strength of Mix 3$\mathrm{B}$ and 5-B was statistically significant different than that of the baseline mix (Mix 2-B) $\left(p=0.021\right.$ and $p=2.5 \times 10^{-3}$, respectively), whereas the average splitting tensile strength of Mix 1-B and 4-B was not statistically significant different from that of the baseline mix $(p=0.36$ and $p=0.24$, respectively). The increase in splitting tensile strength when adding HRWR (Mix 3-B) to the baseline mix was $15.7 \%$. However for Mix B, the largest influence on the splitting tensile strength was caused by internal curing. By replacing concrete sand with lightweight sand (Mix 5-B), the splitting tensile strength increased $21.1 \%$. Fig. 5 shows, as also determined from one-way ANOVA, that the addition of fibers did not have a statistically significant influence on the splitting tensile strength.

\subsection{8-day shear strength}

Fig. 6 shows the results from the 28-day shear strength tests and the average void contents of the specimens tested for the particular mix designs. Shear strength has never before been previously presented on cylinder specimens so no comment 
can be made regarding the variability as compared to other results.

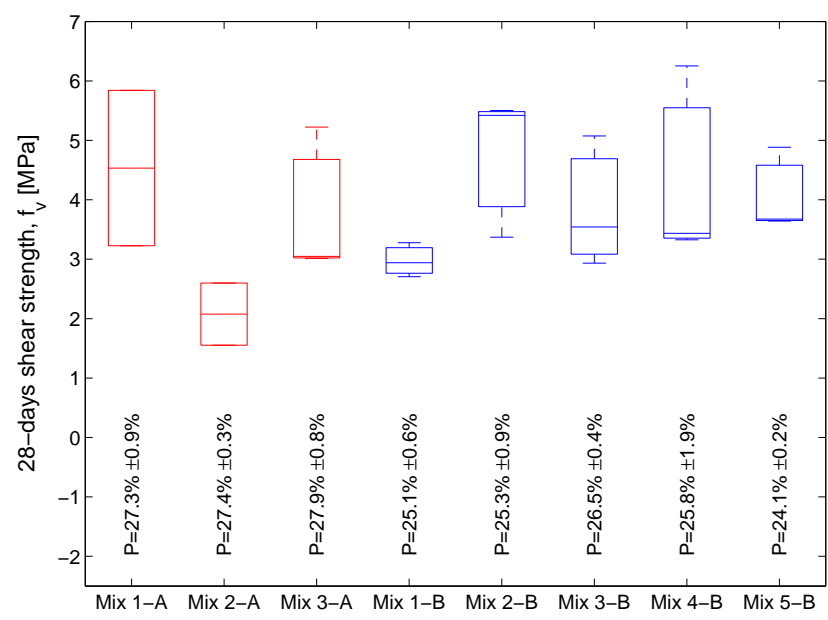

Fig. 6 Box plot of 28-day shear strength, $\mathrm{f}_{v}$, for all mixes. The average void content for the specimens tested is also shown. Three specimens were tested for each mix design.

The average shear strengths are summarized in Table 4 . The variability on the 28-day shear strengths was considerably higher than for the 28-day compressive strengths and splitting tensile strengths, and it makes it more difficult to base any conclusions on Fig. 6. For Mix A, Fig. 6 shows that the 28-day shear strength of Mix 2-A was significantly less than that of Mix 1-A and 3-A. The average shear strength of Mix 3-A was $81.1 \%$ larger than that of Mix 2-A. For Mix B, one-way ANOVA showed that there were no statistically significant differences between the average 28-day shear strength of any of the mix designs.

\subsection{Permeability}

Fig. 7 shows the results from the permeability tests and the average void contents of the specimens tested for the particular mix designs. The average permeability coefficients are summarized in Table 5.

Table 5 Permeability coefficients, $k$, for all mixes. Average (avg.) values as well as coefficients of variation (COV) are shown.

\begin{tabular}{l|ccc|ccccc}
\hline Mix & $1-\mathrm{A}$ & $2-\mathrm{A}$ & $3-\mathrm{A}$ & $1-\mathrm{B}$ & $2-\mathrm{B}$ & $3-\mathrm{B}$ & $4-\mathrm{B}$ & $5-\mathrm{B}$ \\
\hline Avg. [cm/s] & 1.02 & 0.99 & 0.93 & 0.65 & 0.65 & 0.82 & 0.69 & 0.60 \\
COV [\%] & 18.7 & 4.3 & 5.8 & 12.8 & 5.9 & 2.8 & 11.9 & 9.3 \\
\hline
\end{tabular}

The permeability of Mix B was less than that of Mix A because the coarse aggregate for Mix B (granite B) was finer than that for Mix A (granite A) causing Mix B to have smaller diameter pores. As determined by one-way ANOVA

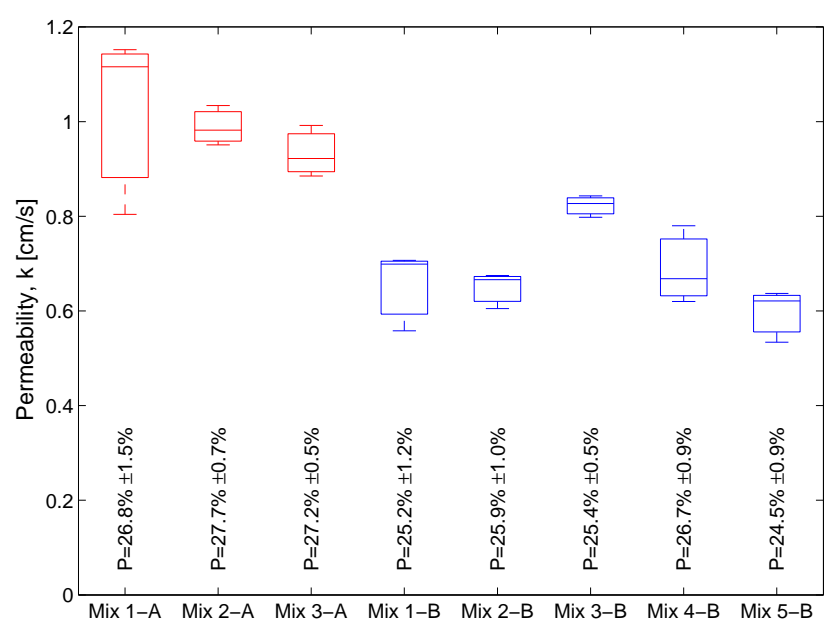

Fig. 7 Box plot of permeability, $k$, for all mixes. The average void content for the specimens tested is also shown. Three specimens were tested for each mix design.

and paired-samples t-test there were no statistically significant differences between the average permeability of mixes A $(p=0.54)$ or mixes B $(p=0.86)$; however, there was a statistically significant difference between the average permeability of Mix 3-B (with HRWR) and the remaining B mixes. The average permeability of Mix 3-B was $26.2 \%$ larger than that of the baseline mixture (Mix 2-B); however, the same tendency was not observed for Mix A.

Overall, the mix designs tested in the present study had average permeability coefficients of $0.60-1.02 \mathrm{~cm} / \mathrm{s}$ which is more than sufficient to drain the rain from a 10 -year rain event in Denmark that has a maximum intensity of 0.004 $\mathrm{cm} / \mathrm{s}$ (IDA Wastewater Commission, 2006). In fact, the PCPC mixes in the present study can drain the rain from a 100-year rain event in Denmark because the maximum intensity of such rain event is $0.007 \mathrm{~cm} / \mathrm{s}$. Thus, for application in PCBs, the permeability of PCPC is considered sufficient. On top of that, for most PCBs, a road surface of either concrete or asphalt concrete is expected to be placed on the PCPC fill, by which the requirements to the permeability of the PCPC fill is even less. Thus, as for most PCPC applications, the permeability and flow rate through the subgrade, in this case at the bridge ends, are restrictive.

\subsection{Freeze-thaw durability}

The freeze-thaw durability was evaluated for all mixes except Mix 1-A. Three beam specimens were tested for each mix and a large variation in the freeze-thaw behavior was observed within each mix. Fig. 8 shows the remaining mass as function of the number of frost cycles, and for the sake of simplicity, only the behavior of a single beam specimen for all mix designs is shown. The specimens representing each mix design in Fig. 8 are chosen as the specimens that experi- 
enced the second least mass loss. The failure mechanism for the specimens was either complete deterioration into cement paste-coated aggregate pieces or fracture of the intact beam into two or three large pieces.

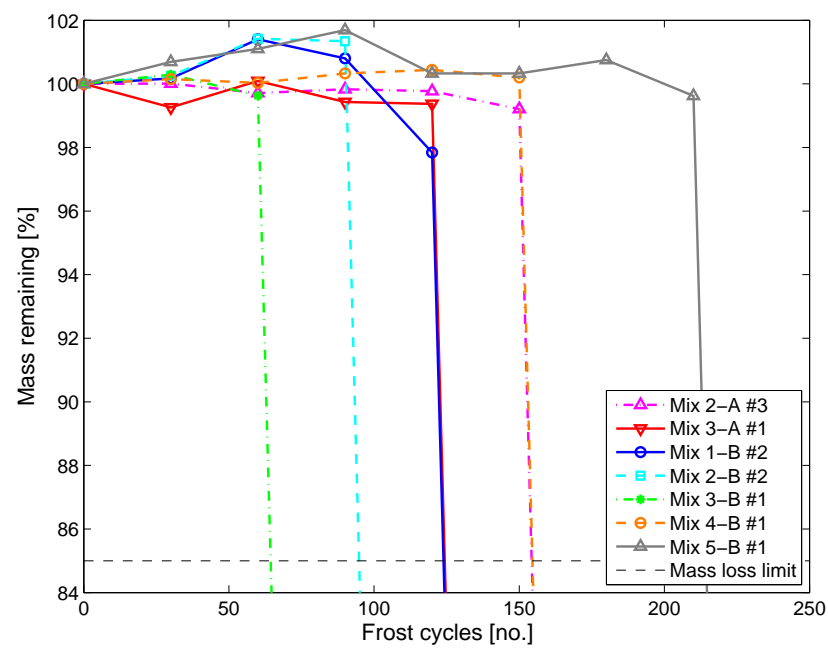

Fig. 8 Remaining mass as function of number of frost cycles for a single specimen from Mix 2-A, 3-A, 1-B, 2-B, 3-B, 4-B and 5-B. Because a certain variation was observed within each mix design, the results should not be seen isolated but in the light of Table 6 .

Although specimens were first soaked in water before initial testing, Fig. 8 also shows that some specimens gained weight during the freeze-thaw tests. This is because the cement paste absorbed water when the specimens were immersed and cycled. The weight gain was largest for Mix 5-B that contained lightweight sand, which is because lightweight sand has a high water absorption due to its large porosity. Moreover, Fig. 8 shows that the mass loss of most PCPC specimens was insignificant until the point of failure at which an abrupt decrease in the mass occurred. At the point of failure the mass loss was set to $100 \%$ and linear interpolation was used to determine the number of frost cycles it took each specimen to exceed the maximum acceptable mass loss which is defined as $15 \%$. Table 6 shows the number of frost cycles at which this mass loss limit was reached for all specimens. Table 6 also provides a description of the observed condition of the samples at failure. The A mixes failed by breaking into two or three large pieces without any significant freeze-thaw type deterioration. In PCPC specimens with high void content or large pores, such as Mix A, the hydraulic stresses from the expanding water can be sufficient enough to cause this loading type failure. All category B mixes with the smaller coarse aggregate experienced a traditional paste failure, except for Mix 5-B which failed through cracking from structural loading caused by ice expansion.

Fig. 9 shows the decrease in RDM calculated from Eq. (4) as a function of the number of freeze-thaw cycles, and the $60 \%$ cut-off limit. The same specimens as depicted in
Fig. 8 are shown. Mix 2-A, 4-B and 5-B experienced a small drop in RDM after 30 frost cycles which is due to the uncertainties related to this test method rather than an actual decrease and subsequent increase in RDM. It should be noted that RDM testing uses a small accelerometer placed on the sample surface which evaluates excitation of the sample from an impact hammer. The low density of PCPC specimens and presence of loose particles on the surface results in more variability than for plain concrete.

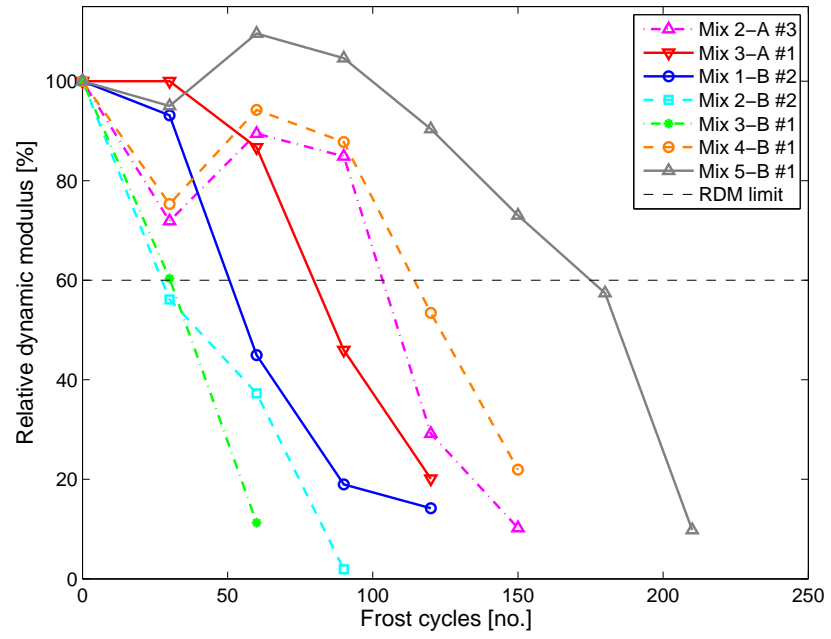

Fig. 9 RDM as function of number of frost cycles for a single specimen from Mix 2-A, 3-A, 1-B, 2-B, 3-B, 4-B and 5-B. Because a certain variation was observed within each mix design, the results should not be seen isolated but in the light of Table 6 .

Compared to the decrease in mass loss, the decrease in RDM occurred faster and more gradually, and most specimens failed due to RDM exceeding its cut-off value rather than the mass. Table 6 also shows the average $D F$ s calculated from Eq. (3). The equation shows that $D F$ is very dependent on the choice of $M$ and $P$ which means that it is only reasonable to compare $D F$ s calculated under the same assumptions. It would be more reasonable to directly compare the decrease in RDM; however, since it is normal standard to evaluate the freeze-thaw behavior of PCPC from $D F$, this is also done in the present study, and the values used for $M$ and $P$ are chosen as typically values used for PCPC (Kevern $e t$ al., 2010, 2015; Shu et al., 2011). The results in Kevern et al. (2010) and Shu et al. (2011) suggest that acceptable freezethaw behavior occurs for $D F$ s larger than $40 \%$; hence, the $D F$ s found in this study are slightly low which indicate that the freeze-thaw durability of the specimens were not good as compared with values normally applied to conventional concrete. The same conclusion was reached from the mass loss consideration, where all mix designs had at least one specimen failing before it reached 100 frost cycles. The freezethaw durability results were much more variable than what is typically observed and allowable for conventional concrete. 
Table 6 Void content of beam specimens exposed to freezing and thawing, durability factors, $D F$, and the number of frost cycles, $n$, for all specimens, and the average number, at which the mass loss is $15 \%$. Average (avg.) values and coefficient of variations (COV) are shown for the void content and the $D F$ 's.

\begin{tabular}{|c|c|c|c|c|c|c|c|}
\hline \multirow{2}{*}{ Mix } & \multicolumn{2}{|c|}{$D F[\%]$} & \multicolumn{4}{|c|}{$n[-]$} & \multirow{2}{*}{ Observed failure } \\
\hline & Avg. & $\mathrm{COV}$ & \#1 & \#2 & \#3 & Avg. & \\
\hline $2-\mathrm{A}$ & 18.6 & 9.6 & 154 & 184 & 124 & 154 & Fracture into large pieces \\
\hline $3-\mathrm{A}$ & 20.0 & 22.0 & 124 & 124 & 184 & 144 & Fracture into large pieces \\
\hline $1-B$ & 16.3 & 55.1 & 86 & 124 & 184 & 132 & Complete deterioration \\
\hline 2-B & 12.0 & 91.0 & 183 & 95 & 34 & 104 & Fracture and deterioration \\
\hline $3-\mathrm{B}$ & 10.5 & 88.3 & 64 & 64 & 125 & 84 & Complete deterioration \\
\hline $4-B$ & 17.4 & 30.9 & 155 & 94 & 154 & 134 & Fracture and deterioration \\
\hline $5-B$ & 26.3 & 47.3 & 214 & 214 & 64 & 164 & Corner broke off \\
\hline
\end{tabular}

Table 6 and Figs. 8 and 9 indicate that the freeze-thaw durability of Mix 2-A and 3-A was similar. For Mix B, the results indicate that there was no significant improvement in the freeze-thaw behavior when adding AEA. The freezethaw durability of Mix 1-B (no AEA) was better than that of Mix 2-B and 3-B (with AEA). Hence, the results indicate that the AEA dosage used was not sufficiently high to create the necessary protective entrained air system in the cement paste. A possible explanation of the lacking entrained air content could be the high fly ash content used in this study compared to other studies where good freeze-thaw results have been obtained with a similar AEA dosage but without fly ash (Kevern et al., 2010). It is expected that improved durability results would be obtained with an increased AEA dosage. For Mix B, Mix 3-B (with HRWR) had the worst durability, and Mix 5-B (with lightweight sand) had the best durability. The beam specimens from Mix 3-B and 5-B had similar void contents and those were the lowest of all specimens tested in this study (Table 3). A low void content is known to improve the freeze-thaw durability of PCPC; however, it has not improved the durability of Mix 3-B. It has been hypothesized that after the water saturated voids in lightweight aggregate empty during hydration the resulting void space is available to improve freeze-thaw durability. These results therefore suggest that lightweight sand can be used to improve the freeze-thaw durability of PCPC. While the freeze-thaw response of these mixtures was lower than considered acceptable for conventional concrete, it is functionally impossible for complete saturation of the PCPC fill layer in PCBs so even the durability level recorded for these mixtures should be sufficient in practice.

\section{Conclusions}

In the present study it was investigated how the mix design of the pervious concrete fill in Pearl-Chain Bridges can be improved by use of air entrainment, high-range water reducer, fibers and through internal curing; however, the research results also apply to pervious concrete used for other purposes. The investigation involved consideration of the compressive strength, splitting tensile strength, shear strength, permeability, and the freeze-thaw durability of eight different mix designs using two different coarse aggregate gradations and two w/c-ratios. The main conclusions from the study were as follows:

1. The void content of pervious concrete decreased when decreasing the maximum aggregate size and increasing the w/c-ratio from 0.29 to 0.31 .

2. The addition of air entrainment and high-range water reducer increased the workability of pervious concrete. Thus, addition of air entrainment and high-range water reducer eases the placement of pervious concrete fill in Pearl-Chain Bridges.

3. The addition, of particularly, high-range water reducer and lightweight sand (expanded shale) for internal curing improved the strength properties significantly. The addition of high-range water reducer increased the 28day compressive strength and the 28-day splitting tensile strength with up to $36 \%$ and $27 \%$, respectively, and the addition of lightweight sand increased the 28-day compressive strength with $25 \%$ and the 28 -day splitting tensile strength with $21 \%$ compared to the baseline mixture. The addition of fibers increased the 28-day compressive strength with $12 \%$ but did not influence the 28-day splitting tensile strength.

4. The aggregate gradation was the predominant factor with respect to the permeability. The larger the aggregates, the higher the permeability. The permeability coefficient for all mixes was $0.60-1.02 \mathrm{~cm} / \mathrm{s}$ which is more than sufficient to drain the rain from a 100 -year rain event in Denmark with a maximum intensity of $0.007 \mathrm{~cm} / \mathrm{s}$. Thus, for Pearl-Chain Bridges with pervious concrete fill, the permeability coefficient of the sub-grade at the bridge ends is restrictive.

5. The air entrainment dosage of $0.125 \%$ of the cementitious material mass was too low to create a sufficiently fine entrained air content that could improve the freezethaw durability of the specimens. Therefore, the freezethaw durability of all specimens was less and much more 
variable than what is typically observed and allowable for conventional concrete. The decrease in the relative dynamic modulus was faster and more gradual than the decrease in the mass during the freeze-thaw tests. Most specimens were considered failed due to reduction in the relative dynamic modulus rather than due to reduction in mass. The freeze-thaw durability of the specimens containing lightweight sand (expanded shale) was improved compared to the other mix designs.

6. Fully-saturated, rapid, freeze thaw testing as used in this study is not representative of field conditions for pervious concrete used as a permeable pavement and even less representative when pervious concrete is used in Pearl-Chain Bridges. The industry is in need of a more representative standard for testing pervious concrete which would allow a true comparison as relatable to field results.

\section{References}

ASTM Standard C29/C29M-09. Standard Test Method for Bulk Density ("Unit Weight") and Voids in Aggregate. West Conshohocken, PA: ASTM International; 2009. doi: 10.1520/C0029_C0029M-09.

ASTM Standard C39/C39M-14a. Standard Test Method for Compressive Strength of Cylindrical Concrete Specimens. West Conshohocken, PA: ASTM International; 2014. doi: 10.1520/C0039_C0039M-14A.

ASTM Standard C136-06. Standard Test Method for Sieve Analysis of Fine and Coarse Aggregate. West Conshohocken, PA: ASTM International; 2006. doi: 10.1520/C0136-06.

ASTM Standard C150/C150M-12. Standard Specification for Portland Cement. West Conshohocken, PA: ASTM International; 2012. doi: 10.1520/C0150_C0150M-12.

ASTM Standard C192/C192M-14. Standard Practice for Making and Curing Concrete Test Specimens in the Laboratory. West Conshohocken, PA: ASTM International; 2014. doi: 10.1520/C0192_C0192M-14.

ASTM Standard C311/C311-13. Standard Test Methods for Sampling and Testing Fly Ash or Natural Pozzolans for Use in Portland-Cement Concrete. West Conshohocken, PA: ASTM International; 2014. doi: 10.1520/C0311-13.

ASTM Standard C496/C496M-11. Standard Test Method for Splitting Tensile Strength of Cylindrical Concrete Specimens. West Conshohocken, PA: ASTM International; 2011. doi: 10.1520/C0469_C0469M-14.

ASTM Standard C618-12a. Standard Specification for Coal Fly Ash and Raw or Calcined Natural Pozzolan for Use in Concrete. West Conshohocken, PA: ASTM International; 2012. doi: 10.1520/C061812a.

ASTM Standard C666/C666M-03. Standard Test Method for Resistance of Concrete to Rapid Freezing and Thaw- ing. West Conshohocken, PA: ASTM International; 2008. doi: 10.1520/C0666_C0666M-03R08.

ASTM Standard C1688/C1688M-13. Standard Test Method for Density and Void Content of Freshly Mixed Pervious Concrete. West Conshohocken, PA: ASTM International; 2013. doi: 10.1520/C1688_C1688M-13.

ASTM Standard C1754-12. Standard Test Method for Density and Void Content of Hardened Pervious Concrete. West Conshohocken, PA: ASTM International; 2012. doi: 10.1520/C1754_C1754M-12.

ASTM Standard C1761/C1761M-13b. Standard Specification for Lightweight Aggregate for Internal Curing of Concrete. West Conshohocken, PA: ASTM International; 2013. doi: 10.1520/C1761_C1761M-13b.

Halding PS, Hertz KD, Schmidt JW. Precast Pearl-Chain concrete arch bridges. J Eng Struct, 2015b;103:214-27.

Henderson V, Tighe S. Evaluation of pervious concrete pavement performance in cold weather climates. Int J Pavement Eng. 2012;13(3):197-208. doi: 10.1080/10298436.2011.572970.

Hertz KD. Super-light SL-Deck elements with fixed end connections. In: Proceedings of fib Symposium; 2015 May 18-20; Copenhagen, Denmark. p. 465-66.

Hertz KD, Castberg A, Christensen J. Super-light concrete decks for building floor slabs. Structural Concrete Journal of the fib, 2014;3.

Kevern JT. Reducing the curing requirements of pervious concrete using prewetted lightweight aggregate for internal curing [Internet]. Kansas City, MO: University of Missouri-Kansas City; 2013. Available from: http://www.escsi.org/uploadedFiles/Technical_Docs/Internal_Curing/Pervious\%20Report\%20-\%20Kevern.pdf.

Kevern JT, Biddle D, Cao Q. Effect of macro-synthetic fibers on pervious concrete properties. J Mater Civil Eng. 2015;27(9):119-34. doi: 10.1061/(ASCE)MT.19435533.0001213.

Kevern JT, Schaefer VR, Wang K, Suleiman ST. Pervious concrete mixture proportions for improved freeze-thaw durability. J ASTM Int. 2008;5(2):JAI101320.

Kevern JT, Wang K, Schaefer VR. Effect of coarse aggregate on the freeze-thaw durability of pervious concrete. $\mathrm{J}$ ASTM Int. 2010;22(2):469-75.

Lund MSM, Hansen KK, Truelsen R, Johansen L. Pervious concrete fill in Pearl-Chain Bridges: Using small-scale results in full-scale implementation. Constr Build Mater. 2016;106:404-14.

National Ready Mixed Concrete Association (NRMCA). Freeze-thaw resistance of pervious concrete. Silver Spring, MD: NRMCA; 2004.

IDA Wastewater Commission. Regional variation of extreme rain in Denmark - a new analysis, 1979-2005. Pamphlet No. 28. Copenhagen: The Commission; 2006. ISBN: 87-7923-502-6. Danish. 
Schaefer VR, Wang K, Suleiman MT, Kevern JT. Mix design development for pervious concrete in cold weather climates. Ames, IA: National Concrete Pavement Technology Center and Iowa State University; 2006.

Shu X, Huang B, Wu H, Dong Q, Burdette AG. Performance comparison of laboratory and field produced pervious concrete mixtures. Constr Build Mater. 2011;25:3187-92.

Tennis PD, Leming ML, Akers DJ. Pervious concrete pavements. EB302.02, Skokie, IL: Portland Cement Association, Silver Spring, MD: and National Ready Mixed Concrete Association; 2004.

Test Method No. Iowa 406-C: Method of test for determining the shearing strength of bonded concrete. Des Moines, IA: Iowa Department of Transportation; 2000. 